\title{
Drawings as spaces for intellectual play
}

\section{Wood, E. \& Hall, E.}

\section{Abstract}

The aims of this paper are to explore the links between drawing and playing and to conceptualise drawings as spaces for intellectual play. The empirical research that supports this position (Hall, 2010a) is based on an interpretivist study involving 14 children age 4-6 in a primary school in England. Over a one year period, 882 drawings were collected from home and school contexts, with commentaries and interpretations given by the children, their parents and class teacher. Expanding on the main findings, three themes were identified that link play and drawing: playing at drawing, playing in drawings, and playing with drawings. The study builds on contemporary interpretations of socio-cultural theories in which drawings are theorised as intellectual play (Moyles, 1989) and as authoring spaces for children's identities (Edmiston, 2008). By playing at, in and with their drawings children reveal the complex imaginative and meditational processes that underpin their playful transformations of their social and cultural worlds, in which concepts of power, agency and identity are embedded (Hall, 2010b; Hall and Wood, forthcoming). The findings propose that play and drawing should be seen as mutually constitutive socio-cultural practices of young children, and as private and public spaces for imaginative and intellectual play. This theoretical position also contests narrow policy versions of play and drawing as servants to socially valued developmental and educational goals.

\section{Introduction}

The aims of this paper are to explore the processes that link drawing and playing and to conceptualise drawings as spaces for intellectual play. The empirical research that supports this theoretical position (Hall, 2010a) is informed by contemporary interpretations of sociocultural theories in which children are seen as agents in their own learning and development (Edwards, 2009). From this position, play and drawing are seen as mutually constitutive socio-cultural practices of young children, and as private and public spaces for imaginative and intellectual activity. The first section reviews contrasting theoretical and disciplinary perspectives on play, and argues that the focus on play as learning and development has obscured children's meanings and purposes, and the importance of play as a social practice (Wood, 2010). This is linked to a critique of the limitations of research on the educational purposes of drawing as a pre-cursor to artistic and literacy development (Hall, 2009). The 
second and third sections report the empirical research, focusing respectively on the research design and methods, and the data analysis, which centres on the three interlinked themes of playing at, in and with drawings. In the fourth section, the discussion considers the findings in light of contemporary interpretations of post-Vygotskian theories, which foreground concepts of power, agency and identity. The conclusion contests the narrow functions of play and drawing as servants of developmental and pedagogical functions, and argues that by conceptualising drawings as spaces for intellectual play, the complexity of children's meanings and socio-cultural interpretations can be understood.

\subsection{Play as learning and development}

Within the broad field of play scholarship, it is well-established that children engage in many forms of play in order to understand their social and cultural worlds, to communicate and express their understanding in creative ways, to develop social networks, and to construct knowledge and skills (Wood, 2009). Research evidence shows important benefits for learning and developmental processes, as well as for discipline-based learning in the curriculum areas (Bodrova, 2008). Play activities are considered to be particularly effective for children's communicative, narrative and representational competence, through symbolisation, and multi-modal forms of expression such as painting, modelling, collage, sculptures and drawing (Anning and Ring, 2004; Carruthers and Worthington, 2011). Developmental and pedagogical discourses about play-based learning regard such activities as pathways to more competent, specialised, and skilled performance, often with a focus on socially approved domains and subject disciplines.

A significant theoretical shift in the last thirty years has been away from the dominant developmental stage theories, towards contemporary interpretations of socio-cultural theories. However, whilst post- Vygotskian theories have been used as explanatory frameworks for understanding play, they have influenced justifications for 'educational play'. This involves a continued focus on what play does for children (Hughes, 2010), the role of adults in structuring play (Bodrova, 2008), and the development of cognitive and affective imagination (Diachenko, 2011). The educational discourse defines play from a predominantly functional perspective, and positions play as a form of pedagogy.

In contrast, post-developmental and post-structural interpretations have shifted the focus towards deeper engagement with what children do in their play (Broadhead, Howard and 
Wood, 2010; Brooker and Edwards, 2010), including children's play cultures, cultural variations in their orientations to play, and deeper understanding of play as a social practice that is determined by children's agency, meanings and purposes (Edmiston, 2008; Henricks, 2009; 2010). These perspectives also acknowledge that play is a distinctive form of activity, in which children's motivation to play reflects their need to develop mastery of play, and to enact forms of agency that are often denied to them in other contexts. Sutton-Smith discusses the rhetoric of power within children's play, which actually enters into and helps determine the very forms of much of their play (1997: 122). He argues that children always seek to have their own separate play culture, and within that, resistance against adult power and conventions is a hidden transcript of childhood (1997: 125). Even within educational settings children will seek to assert their own play cultures, in which issues of agency, identity, choice, control, power, subversion, take on different meanings from those ascribed by adults. This aligns with the philosophical stance of Henricks, who argues that

The true spirit of play is the burst of creative expression, the awareness that subjectivity can re-make the world in patterns of its choosing. Following rules is not a distinctively playful act: manipulating, circumventing, or otherwise 'tweaking' those rules for one's own pleasure is. (Henricks, 2010: 193)

Play activities often provide children with opportunities for experimental, creative and transformational processes where they can manipulate and change the meaning of time, space, tools, artefacts and events. This conceptual position reflects the definition of play not as a set of functions, but as a family of action features that make up the meaning of play, involving a kind of communication (a mode) and a kind of action, which integrate internal and external behaviours (Sutton-Smith, 1997:23). This definition is used here to explore the relationship between play and drawing.

\subsection{Drawing as learning and development}

In common with play, research on children's drawings is located in different disciplinary traditions, notably psychology and art. Many theorists have proposed models of artistic development which invariably focus on linear progression in drawing ability (e.g. Luquet, 1927/2001). These models describe the progression of children's drawings from meaningless, abstract scribbles to meaningful, detailed representations (Matthews, 1997). However, many researchers question the value of stage theories and the placing of visual realism as the pinnacle of artistic achievement, especially to the neglect of other expressive and aesthetic qualities (e.g. Pariser, 1995; 1999). Despite the wide application of 
developmental frameworks to the analysis of children's drawings, there is no single stage theory that is universally unchallenged and accepted (M. Cox, 2005). Nonetheless, the influence of stage theories can account for adults judging children's drawings on the basis of their realism and equating a good drawing with a life-like drawing. These theories have also led to the belief that drawings are indicators of intelligence, thus a child who is able to make a detailed drawing is more cognitively advanced that a child whose drawing is less detailed. However, this view does not account for children choosing to include only those details that they decide are essential to their drawing intentions (Arnheim, 1974; Golomb, 1974).

Within an educational and developmental discourse, Hall (2009) has analysed the ways in which drawing is often positioned as an emergent or pre-writing skill, as evidenced in national curriculum frameworks in England. This position has been influenced by Vygotsky's theories on the prehistory of written language (1978), because socio-cultural theories of development propose that early forms of drawing and writing are undifferentiated in spontaneous graphic representations. A major transition takes place from discovering that one can draw not only things but also speech (1978: 115). Thus in an educational discourse, writing becomes more socially valued than drawing because it represents children's transition towards formalised literacy with its own system of rules and social conventions. Similarly, from the perspective of art, children's spontaneous drawings are commonly valued and assessed on their visual realism or aesthetic merit, and not on the purposes they serve. However, although Vygotsky proposed the notion that make-believe play, drawing and writing can be viewed as different moments in an essentially unified process of development of written language (1978: 116), these processes have not been clearly defined either separately or in combination. Vygotsky privileged (as other researchers have done subsequently) the progression from drawing to writing which has arguably set the pattern for the ways in which drawing (like play) has been positioned as the servant to progression in forms of disciplinary knowledge (Hall, 2009).

In contrast to these disciplinary perspectives, research within ethnographic and ecological theoretical orientations explores the ways in which drawing is much more than a pre-writing skill, or a developmental transition from 'drawing things to drawing speech'. The focus is on understanding the more complex purposes that drawing fulfils for young children, as an intrinsically valuable form of abstraction and communication, as a social practice, and as a symbolic means of bridging home and school contexts (Hall, 2010a; Einarsdottir et al, 2009). Anning and Ring (2004) collected the drawings of seven children in England over a three 
year period, using scrapbooks and photographs as modes of recording children's drawings, with examples of children's play activities. Explanatory notes were written by parents and key workers, alongside interviews with parents, teachers and the children. Combining these data in case studies for each child, Anning and Ring created an interplay of narratives that incorporated speech, play, drawing and symbolic representations, and illustrated cognitive, affective and aesthetic aspects of understanding. Drawings are also seen as the child's own forms of expression and meaning-making, including their thoughts, feelings, and interpretations of experiences and everyday events in their lives. Ahn and Filipenko (2007) conducted a small-scale phenomenological study of six children ( 3 boys and 3 girls, age 5) in an early childhood education centre in Canada, utilizing children's narratives of their imaginative play and drawings, including descriptions of their visual texts, and episodes of imaginary play. The findings indicate the ways in which young children represent themselves and others in the narrative roles and scripts that they create in their imaginary play and visual texts. Children's narratives not only represent experience, as they know it to be, but also represent experience, as they would like it to be (Ahn and Filipenko, 2007: 279), which links to the concepts of play as imagined power and creative expression. Similarly, S.Cox (2005) theorises drawings as a cultural resource; the young children in her study used their drawings in playful ways to make jokes and share stories, and meanings about the drawings were constructed and negotiated within a social context. From this perspective, drawings are similar to play scripts because they become children's intentional representations of thought and activity, in which they interpret roles, identities, and feelings.

These findings are consistent with research studies that take an ecological perspective on literacy as a social practice, and identify the development of multi-literacies, in which symbols and texts are seen as intellectual tools (Kress, 1997; Pahl, 1999; Wright, 2007). Research on children's narratives in art and play activities identifies the importance of signs and tools, and the ways in which these are used as meditational means within activities. In Vygotskian theory (1934/1976) words are objects or semiotic tools which serve a mediating role as children make sense of their social and cultural worlds. Children's drawings and other play narratives are a form of cultural transmission of their everyday knowledge, their imaginative capabilities, and their invented meanings. They convey playful and humorous experiences and interpretations of their everyday worlds, for example through different art forms; narratives, songs, rhymes and riddles; factual, fictional and mythic stories. Imaginative play enables children to express their thoughts, ideas, emotions, purposes and meanings: as they create play narratives together, they intertwine their own stories and life 
experiences. As Edmiston argues (2008) the overlap of everyday space and imagined space is ever-present, because children's imagined spaces have their roots in everyday spaces.

The content of children's imaginative play is often expressed through signs and symbols which serve particular functions, and convey meanings which are often created at a metalevel, in that children simultaneously create imaginative transformations, and communicate these in different modes. Therefore children are not just 'acquiring' cultural tools, but are using them as intellectual tools in inventive and transformative ways. In imaginative play activities, children act via mediated social interactions, and via relationships between the players, in ways that lead towards intersubjective attunement and shared perspectives that are essential to maintaining play. Thus the role of drawings may be enhanced, because these take on the meta-communicative status of symbolic tools and artefacts which mediate collaborative activities. This position aligns with that of Henricks (2010) who argues that researchers must not set play apart but rather set is beside other kinds of activity as a way of appreciating both what play has in common with these other forms and what makes it different (2010: 190, italics in original). This leads to a new position for considering the common characteristics of play and drawing.

\subsection{What do play and drawing share as common characteristics?}

Moyles (1989) proposed that drawing is a form of intellectual play because both are characterised by specific qualities, including aesthetics, imagination, fantasy, reality and innovation. However, the processes that link play and drawing need more detailed exploration, both theoretically and empirically. A fundamental characteristic of play as intellectual activity is that it involves some kind of transformation, for example, making what is present absent, or what is absent present (Sutton-Smith, 1997: 127). Furthermore, this theoretical stance goes beyond understanding children's meanings and perspectives, and incorporates children's agency - how they act in and on the world, and how they transform their everyday experiences through narratives and symbolic representations. This is paralleled by Bruner's theories on the creative processes of art-making: 'the artist creates possible worlds through the metaphoric transformation of the ordinary and the conventionally given' (1986: 9). For Edmiston, the concept of transformation is linked to the ways in which children explore possible selves and identities. He argues that play events 
involve combining everyday experiences with imagination: in between everyday and imagined spaces there is an authoring space for self:

Authoring occurs in a projective-reflective space. Playing is projecting a possible self into a narrative world and through interactions creating images of a play world. Every narrative, whether from a book, a movie, or a told story, provides people with possible ways of being, acting and relating to other people (Edmiston, 2008: 10)

The implications of these theories for the purposes of this study are to understand what transformations are occurring, in the minds of the children, via their actions in and on their play worlds, and via their narrative interpretations of the drawings. These transformations may be context dependent in relation to children's choices, specifically their choices to draw, about the content of their drawings, and about forms of representation. Thus drawings, like play, reveal the hidden transcripts of childhood. This adds another significant theoretical and methodological challenge, namely to understand play and drawing not only from children's perspectives, but also from the perspective that 'this is play'. The following section describes the ways in which these challenges were addressed in the empirical research.

\section{Research methodology and design}

The study (Hall, 2010a) adopts an interpretivist ontology, in which reality is understood from the perspectives and experiences of the research participants (in this case, children, parents and one female class teacher). In common with contemporary views of young children as competent social actors, this methodological position proposes that although they make their own meanings in and through cultural resources, these meanings are determined by pre-existing discourses, such as cultural imagery and cultural meanings (MacNaughton, 2004). The focus on the communicative potential of children's drawings was concerned with what and how children communicate through drawings, and the main influences on their drawings. Thus the drawings were the main focus of the study, rather than a research tool for eliciting children's voices. Following Leitch (2008: 54) the aim was to enable the participant(s) to story, narrate or dialogue with the image(s), thus allowing layers of meaning and significance to emerge. The drawings became a narrative springboard for the construction of inter-subjective meanings. A detailed account of the research design is given in Hall (2010a). 
The study involved children in a mixed Reception (age 4-5) and Year 1 (age 5-6) class in a rural school in England. Fourteen children were selected for in-depth case studies: 8 girls and 6 boys aged, at the start of the study, between 4.8 and 5.11 years. Data were collected over one school year (September to July), in three (termly) seven-week research phases. Ethical procedures included familiarisation with the children by the researcher, using storyboards to communicate the purposes of the research, and to gain informed consent from the children. Spontaneous (non-commissioned) drawings from home and school settings were collected in scrap books and discussed with the children, alongside observations of the children drawing in class. The scrapbooks (one was given to each child at the start of each phase) were discussed with the children each fortnight ( 7 children week A, 7 children week B) in individual, audio-recorded research conversations.

The aim of these open-ended conversations was to explore the children's ideas and meanings, and their interpretations of the drawings. These methods were considered to be appropriate and ethical: the length of the conversations was dependent on how many drawings were in the scrapbook, and how much the children wanted to say about them. Very rarely did they ask to end the conversations, and they were willing and enthusiastic participants. These methods were repeated in each phase, resulting in the collection and analysis of 882 drawings. The children chose their own pseudonyms and throughout the research they were recognised as expert informers and witnesses regarding their own experiences and perspectives (Wood, 2005).

The class teacher (Faye) was interviewed at the beginning and end of each phase (a total of six times), and the children's parents were interviewed once at the end of each term (a total of three times). The data from the adults was valuable for elucidating contextual details of the children's home and school environments and experiences. These data highlighted potential influences on the children's drawings, and enabled a clearer distinction to be made between everyday and imagined events, people and places. For example, although Elizabeth drew a 'little sister' her mother explained that this was not a real sister but a doll she called her little sister.

\subsection{Data analysis}

Using iterative procedures, the drawings were analysed for thematic content, alongside the inter-subjective understandings of content, the children's purposes, and contextual influences on the drawings. The analytical procedures included transcription, coding of each data set, and progressive focusing to build categories to describe the data. Qualitative and 
quantitative methods of analysis were used, to identify patterns and themes, and to explain the communicative potential of the drawings. The quantitative data included the number of drawings collected for each child, the main subject content within the drawings for each phase, (e.g. people) and the main sub-categories (e.g. self, family members, anonymous people, friends, fantasy people, ). Validity and reliability of the analytical processes was established through inter-rater reliability (quantitative data) and informal discussions with colleagues to discuss the researcher's interpretations (qualitative data). In addition, a research diary was kept throughout the study as a means of enhancing reflexivity, particularly with regard to Thompson's argument that an image can be read in multiple ways (2008:10). A summary of the key themes in the findings is given in Table 1:

\section{What do young children communicate through drawing?}

Content strands (Individual drawing preferences)

Communicating identity

Communicating power

Communicating purpose

\section{How do young children communicate through drawing?}

Drawing as a visual language

The importance of talk

\section{What influences young children's communication through drawing?}

Home influences

School influences

Additional influences

Table 1: Summary of main findings (Hall, 2010a)

Expanding on the main findings, three themes relating to play were identified in relation to the children's drawings: playing at drawing, playing in drawings, and playing with drawings. Data from the three phases is used to illustrate these themes and highlight some of the processes that link play and drawing, and how drawings can be conceptualised as spaces for intellectual play. Many of the drawings showed evidence of more than one theme and it should be stressed that alternative interpretations are possible.

\section{Data analysis}

3.1. Theme 1: Playing at drawing 
Playing at drawing was evident during the process of drawing, on physicaland social levels. Data in support of this theme were collected from classroom observations, in addition to anecdotal evidence gained from the teacher and parent interviews. Watts (2010) states that children are more commonly interested in making drawings than in the finished drawings as objects, which is shown in the following examples.

Physical play

It can be argued that most of the drawings involved physical play, as drawing is a physical process that the children often approached in a playful manner. During the activity of drawing children often become involved through whole body actions and accompanying dialogue or sound effects (Matthews, 1999). However, there were some instances where children seemed to take a more physically exuberant approach to making their drawings. One such example was identified during an observational drawing activity of a plant, instigated by the researcher in Phase Two of the study. Faye explained that Beckham (Year 1 boy) had recently become interested in making his work as colourful as possible; this was evident in his plant drawing, which was coloured all over. While Beckham was adding marks to his drawing he started saying "dot, dot, dot" to himself, enthusiastically banging the pen on the paper. The chant then turned into a song. This example shows evidence of playing at drawing on a physical level in terms of visual enjoyment in colour use, kinaesthetic enjoyment in the drawing media, and aural/oral enjoyment in chanting and singing whilst drawing. Although Beckham's plant drawing was non-spontaneous, it was nonetheless playful in relation to how he interpreted the learning activity.

\section{Social play}

Playing at drawing on a social level was evident when the children engaged in playful social interactions during, and related to, the drawing process. The following example describes drawing involving social play from Phase Three of the study. Elizabeth (Year 1 girl) and Tink (Year 1 girl) were sitting side-by-side whilst they both made a drawing featuring each other with friends and family. They discussed the drawings in detail, eliciting each other's opinions on desirable clothing, hairstyles, and facial features. Their exchange of ideas, with some short interruptions, lasted for 55 minutes. The length of this drawing activity demonstrates that, when they are immersed in an enjoyable and stimulating activity, young children's attention spans can last for much longer than is commonly assumed. This example 
is evidence of playing at drawing on a social level because the drawings were made through a process of playful discussion between the two girls, and can therefore be seen as products of their shared ideas. In addition, due to their stylistic similarities, the drawings can be described as having high 'social value' (Scott Frisch, 2006). Drawings produced in this way may also help to maintain friendships (Wang, 2007), because communication about the drawing is essential to establishing and sharing the meanings and actions.

Playful social interactions were also a key feature during the process of large-scale group drawing, which was a popular classroom activity, especially in Phase Two. Faye regarded this as collaborative, interactive process which is valuable for 'communicating what they're thinking'. Observations showed how the children competently shared their knowledge and understanding about what they were drawing. When drawing as individuals there were some instances of competitiveness, but in this more democratic context the children seemed to be constructing powerful shared identities. In addition, jokes were frequently shared about what was considered to be amusing drawing content (S. Cox, 2005): for example, when drawing a tadpole going down a slide, driving a boat, snoring in bed, and going on holiday in an aeroplane. The drawings acted as shared play scripts for combining everyday and imagined events. In common with research on children's mathematical graphics Carruthers and Worthington's (2011), these data show that children's drawings reveal semiotic activities, the products of which evolve in close proximity to the functions they serve in the context of the child's everyday and playful activities.

\subsection{Theme 2: Playing in drawings}

Playing in drawings was evident as subject matter in the drawing as an object, as identified by the children during the research conversations. There were two forms of playing in drawings: physical play and imaginative play. Both forms of playing in drawings involved the depiction of people: most often the children themselves, but also including imagined characters, family members and friends.

Physical play

Physical play in drawings was evident where the children drew figures performing actions such as jumping, dancing, running. Some drawings showed physical play with a variety of 
toys and play equipment, which was one of the content strands identified from the quantitative analysis. An example of a drawing reflecting this theme was made by Kiki (Year 1 girl) in Phase One. Kiki's drawing, made at home, featured herself and her two siblings riding scooters along a road. This example is evidence of playing in a drawing on a physical level as the drawing featured play equipment (the scooters) and play as action (riding the scooters). The drawing allowed Kiki to take a risk in a safe environment because she could play at riding her scooter on the road, free from adult supervision. This drawing contrasts with that of her brother Ben, who drew himself and his scooter in the (safe) context of the family garden.

In Phase Three Red Dragon (Reception boy) drew a picture of himself (smiling) and riding a bike in the woods. In the research conversation the first thing he said was 'No stabilisers! No stabilisers!' This was clearly an episode of some meaning and relevance for him. His mother noted in his scrapbook that he had ridden the bike for the first time without stabilisers in a local wood. Red Dragon pointed out a tree stump and said "I'm sort of doing a wheelie, because I bumped into that tree stump", and demonstrated the action with sound effects. The drawing both depicted physical play and prompted physical play in Red Dragon's response to the drawing. His drawings also featured non-human action such as machines with moving parts, erupting volcanoes and meteorites.

\section{Imaginative play}

All of the drawings involved some imagination and this was a rich and complex area of interest. However, there was evidence of imaginative play in drawings where the children described activities such as dressing up or role-play. An example of a drawing showing imaginative play was made by Red Dragon in Phase One of the study. The drawing, made at home, featured Red Dragon and a television character called Tommy Zoom, an ecosuperhero. Red Dragon explained that a meteorite was going to come and hit the sun, but he would be fine: he possessed more power than Tommy and could fly away. Red Dragon was imagining that he had superhero flying powers, symbolised by the ' $z$ ' (zoom) logo on his clothing. He also communicated a dramatic story where he was positioned as a powerful figure; therefore the drawing offered a transformative space in which to be more powerful than in everyday life (Edmiston, 2008). Another example of imaginative play in drawing was made by Elizabeth in Phase Three in which she drew herself as two characters - teacher and pupil. She explained that she was pretending to be the teacher when she made the 
drawing, and it includes a range of writing, with ticks for correct spelling, and crosses for incorrect spelling. By making deliberate mistakes in her writing she was demonstrating her knowledge of spelling in a playful context.

Bruner proposes that, in order to re-present knowledge in various symbolic forms, the creator needs to have more information available than was required for the ordinary direct experience of that event:

It follows that in drawing an object, one requires somewhat different information about it than one does for manipulating or describing it. In this sense, media of expression and communication are exploratory devices - a point of immense importance to an understanding of the child's acquisition of knowledge (Bruner, 2006: 26) (italics in original)

Bruner's theories can be extended to understand the concept of playing with absence and presence in drawings, because children have to explain what is and isn't there. The children in this study did not represent everything that was happening in an everyday or imagined event, but could explain this in their narrative interpretations. Thus when Tink is playing hide and seek with friends she is outside the house, whilst her friends are inside (and therefore not visible in the drawing). Similarly Ann (dressed as a princess by a castle) is playing hide and seek with her brother, who is not included in the drawing. In his drawing of a beach scene, Ben explains that he, his mother and sister are dancing to pop music, which is too loud and annoying the fish. The radio is not in the picture, but Ben explains that the fish is going to bite the radio and turn it off. These examples also indicate that whilst the act of drawing takes place in 'real time', the development of play themes within the drawings relies on children's memories and motivation. In this study, the drawings act as playful representations of previous, present, future and imagines experiences.

\subsection{Theme 3: Playing with drawings}

Playing with drawings emerged during the research conversations. There were two forms of playing with drawings: physical play and storytelling.

Physical play 
Physical interaction with drawings commonly occurred when children pointed out various features, and used gesticulation to explain movement in their drawings. Wright (2007, p. 43) notes that gesture is an important part of children's 'telling' when discussing their drawings. However, an example of playing with drawing on a physical level was evident in connection with a drawing of a snooker table, made by Beckham (Year 1 boy) in Phase Three of the study. Beckham told the researcher: 'I know how to play snooker', and proceeded to explain in detail (with actions) how to hit the ball to make it go 'where you want it to'. Children often find it difficult to depict movement and action in their drawings (Eng, 1931/1999). However, Beckham did not attempt to draw a game of snooker 'in play', rather his discussion around the drawing showed that he associated the snooker table with action, and his understanding of the rules. Beckham was playing with absence and presence: drawing the snooker table as an object was perhaps sufficient for his drawing intention, but he needed to demonstrate his action in order to share his detailed knowledge of a favourite game.

\section{Storytelling}

Children's drawings carry meaning for their creators, and often act as a narrative springboard for the imaginative content (Wright, 2007). Sometimes the children made drawings that were inspired by familiar stories, and sometimes they constructed stories from their drawings during the research conversations. An example of playing with drawing through storytelling was made by Ben (Year 1 boy) in Phase Two. The drawing, made at home, showed two birds, a canon and a sun with long rays. Ben explained that the sun's rays were long to show that it was very sunny, adding 'I do suns like that, to the edge of the page'. A complex story unfolded around the drawing. He explained that the canon was being fired and "the sun might burst". The conversation about this drawing was unusual, as Ben normally talked about his drawings in straightforward terms, without any volunteered elaboration. In an imaginative drawing, Elizabeth featured a horse with two owners - a nasty one and a nice one. The drawing is in the form of a comic strip, combining writing and action figures. It tells a story and conveys a message about Elizabeth's imagined agency: the man with the gun shouts 'go away', and might shoot the horse. The horse is frowning 'I am gowing (going) to sum (some) one how (who) loves me' and goes to the girl who says 'I love you' The horse is smiling and says 'She lovs (loves) me. I love you to (too)'. This drawing conveys emotion, thought and action: the man represents threat and violence, the girl represents love and care. Children often use imaginative play as a way of playing with 
emotional opposites - love and hate, acceptance and rejection, happiness and sadness, and as a way of exercising agency in relation to imagined choices and dilemmas.

As in play narratives, drawings create images and symbols that are imbued with children's meanings and interpretations. From Wright's (2007) perspective, drawings can be seen as communicative and meta-communicative texts in which children play with contexts, meanings, events, identities and modes of expression. In communicating about and through their drawings, children reveal the paradoxes of play in that they simultaneously distinguish between and combine their everyday and imaginary worlds.

\section{Discussion}

Through detailed analysis of the children's drawings and narratives, three themes were identified: playing at, in and with drawings. In each of these themes, the processes that link play and drawings were revealed, leading to a new theorisation of drawings as spaces for intellectual play. The purpose of the discussion is to justify this theoretical position, and to propose some implications for further research and practice in early childhood education.

The children's drawings reveal the qualities identified by Moyles (1989), aesthetics, imagination, fantasy, reality and innovation. Building on this position, the study describes and illuminates the processes that link play and drawing. For Bruner (1986), symbols and texts are intellectual tools, and the means by which humans seek constantly to cast experience into symbolic codes. In culturally organised forms of knowledge, these are represented, for example, through maps, poems, algorithms, and art forms. In play, children's experiences are cast in symbols and modes of their own inventions. Drawings therefore act as communicative and meta-communicative texts in which children play with contexts, meanings, events, identities and modes of expression. Sutton-Smith (1997) argues that, in play, any meta-communicative autonomy presupposes the fantasising autonomy and intersubjectivity of the player or players. This means that the players control the imaginative content of their play, and communicate this content in ways which can be understood and shared by co-players. The 'meta' qualities of the communication focus on talking about the imaginative contexts, rules of play, plot, characters, narrative directions and so forth. By creating 'possible worlds' and 'metaphoric transformations' (Bruner, 1986) it can be argued that drawings, like play, enable children to make connections between thought, emotions and action, between the everyday and the imagined, and across time and space. From this 
perspective, it can be argued that the processes of translation (from experience to symbol), imagination (re-presentation of the experience through exploration and invention), and communication are the intellectual tools and processes that link play and drawing.

Second, the drawings and research conversations provide evidence of the socio-cultural processes that link play and drawing and create spaces for intellectual play. The drawings reveal individual and social aspects of thought and activity, through the activity of drawing and the activity depicted in the drawing. The content of the drawings is linked to the children's meanings and interpretations of events, as revealed in their conversations within and about the drawings. As such, the content carries symbolic meaning as well as symbolic power. Symbols in children's drawings can signify imagined power: it is not just a process of making one thing stand for something else in a material sense, but making one thing stand as a signifier of personal agency. This was expressed when children drew themselves as other characters, including animals, and in adult roles such as teacher, pirate, superhero, pilot, lighthouse keeper, bride. This evidence suggests that role play is more than just simple imitation of adults or reversal of roles (Hughes, 2010). The drawings convey that children are not just pretending to be another character, but acting 'as if' they have additional imagined power and agency. Moreover, the children do not restrict themselves to the limitations defined by these roles, but often use imagined powers to explore a range of identities.

Third, the findings support Edmiston's (2008) argument that, by combining everyday and imagined spaces in play, children create authoring spaces for their own identities. Because young children find imaginative worlds particularly compelling, they have an intellectual investment in the creating the bridging strategies that link these spaces. By manipulating events, people and symbols, children use drawings as ways of positioning self in relation to others, and as ways of manipulating the feelings, mood and mind states of characters (real or fictional). To paraphrase Henricks (2010), children re-make the world in patterns of their own choosing, in ways that enable them to exercise imagined power and agency.

Many of the drawings in this study, along with the research conversations, reveal the hidden transcripts of children's imaginative play and the complexity of their symbolic activities. Play and playfulness add distinctive qualities to children's drawings because within the 'what if' and 'as if' qualities of imaginary play, meanings have to be conveyed in order for the action to be understood. The narratives about the drawings also reveal the heteroglossia of voices: the child's inner dialogue about her/his play worlds explains the child's position and 
agency within the narrative. These findings resonate with those of Ahn and Filipenko (2007) in which the narratives created by the children revealed the complex journeys they took in the process of forming a self identity, and enabled them to make sense of their sociocultural worlds in factual and emotional ways.

Fourth, in relation to recent critiques of policy-centred views of drawing (Hall, 2009) and play (Wood, 2010), the findings support a more complex conceptualisation of these activities. The evidence from many studies indicates that the children's drawings are not just exploratory devices but transformative devices (Anning and Ring, 2004; Carruthers and Worthington, 2011) that are used to create bridges between different contexts. By playing at, in and with drawings, children demonstrate repertoires of skills and knowledge that have been learned in home and community contexts. Although difficult to define in relation to official curriculum knowledge, nevertheless these repertoires have meaning and relevance for the child, because the skills and knowledge can be used, manipulated and represented in their own ways. Drawings are more than graphicacy or mark-making. Within drawings, the playful use of symbols is unique to the child, or possibly to a group of players. These symbols are not just a developmental precursor to formalised symbol systems such as letters and numerals, because they carry situated meanings that are constructed by the players. Symbols relate not only to things but to the child's identity, agency and power. In the study reported here the children's drawings and conversations revealed transformations of roles and identities, material objects and events. Thus play activities have immediate relevance and purpose for the child and may lead, or be linked to more complex forms of play in other areas of their lives.

\section{Conclusion}

This study makes a significant contribution to developing a complex conceptualisation of drawings as spaces for intellectual play, by identifying the characteristics and processes that link drawing and play. By using the drawings as the visual texts of play, children's interpretations and perspectives were privileged as a means for understanding the hidden transcripts of their everyday and imagined worlds. However, the drawings should not be seen solely as a manifestation of children's play and playfulness. Rather drawing can be seen as an inherently playful activity, in which children can be spontaneous, creative and free from external evaluation. Further research might usefully explore the inter-relationships between play and other art forms such as such as painting, modelling, sculpting, collagemaking. 
The pedagogical implications of this study are problematic. The evidence implies that educators need deep understanding of the meaningfulness of children's play, and the processes that link play and drawing. However, it is argued here that efforts to understand children's perspectives in research and in education settings should acknowledge the tensions that exist between the limited educational purposes of play and drawing in curriculum policies in England (Hall, 2009; Wood 2010), and children's own purposes. Those purposes include the playful ways in which children re-make the world in patterns of their own choosing, through possible ways of being, acting and relating to others. However, children's exercise of power, agency, risk and subversion sits uncomfortably with the normative and socially approved developmental goals in curriculum frameworks. This is a significant point because the educational discourse that positions play and drawing as servants to defined curriculum goals neglects the complex processes and characteristics that have been revealed in this study. 
References

Ahn, J. amd M. Filipenko. 2007. Narrative, imaginary play, art, and self: Intersecting worlds. Early Childhood Education Journal 34, no. 4: 279-289.

Anning, A. and K. Ring. 2004. Making sense of children's drawings. Maidenhead: Open University Press.

Arnheim, R. 1974. Art and visual perception: a psychology of the creative eye (new version). Berkley, LA. University of California Press.

Bodrova, E. 2008. 'Make-believe play versus academic skills: a Vygotskian approach to today's dilemma of early childhood education', European Early Childhood Education Research Journal, 16: 3, 357-369

Brooker, L. and Edwards, S. 2010. Engaging Play, Maidenhead, Open University Press.

Bruner, J. 1986. Actual minds, possible worlds. Cambridge, MA: Harvard University Press.

Bruner, J. 2006. Symbols and texts as tools of the intellect, in J.S. Bruner, In search of pedagogy, Volume II. The selected works of Jerome S. Bruner, 21-34. London, Routledge.

Carruthers, E. And Worthington, M. 2011. Understanding children's mathematics, beginnings in play.Maidenhead, McGrawHill Open University Press.

Cox, M. 2005. The pictorial world of the child, Cambridge, Cambridge University Press.

Cox, S. 2005. Intention and meaning in young children's drawing. International Journal of Art \& Design Education 24, no. 2: 115-125.

Diachenko, O. 2011. On major developments in preschoolers' imagination, International Journal of Early Years Education, 19(1) 19-25.

Edmiston, B. 2008. Forming ethical identities in early childhood play. Abingdon: Routledge.

Edwards, S. 2009. Beyond developmentalism: interfacing professional learning and teachers' conceptions of sociocultural theory. In S. Edwards. and J. Nuttall, eds. Professional Learning in Early Childhood Settings, 81-97. Netherlands: Sense Publications.

Einarsdottir, J., S. Dockett, and B. Perry. 2009. Making meaning: children's perspectives expressed through drawings. Early Child Development and Care 179, no. 2: 217-232.

Eng, H. 1931/1999. The psychology of children's drawings: From the first stroke to the coloured drawing, trans. H. Stafford Hatfield. London: Routledge.

Golomb, C. 1974. Young children's sculpture and drawing. Cambridge, MA: Harvard University Press. 
Hall, E. 2009. Mixed messages: The role and value of drawing in early education. International Journal of Early Years Education 17, no. 3: 179-190.

Hall, E. 2010a. The Communicative potential of young children's drawings. Unpublished thesis for the degree of PhD, University of Exeter, UK.

Hall, E. 2010b. Identity in Young Children's Drawings: Power, Agency, Control, and Transformation. In Play and learning in the early years, eds. P. Broadhead, J. Howard and E. Wood, 95-112. London: Sage.

Hall, E. and Wood, E. (forthcoming) Play and drawing as authoring spaces for children's identities.

Henricks, T.S. 2009. Play and the rhetorics of time: progress, regression, and the meanings of the present, in D.Kuschner, ed. From Children to Red Hatters Diverse Images and Issues of Play, Vol: 8, 14-38. Maryland, University Press of America.

Henricks, T.S. 2010. Play as ascending meaning revisited: four types of assertive play, in Nwokah, E., ed. Play as Engagement and Communication, Play and Culture Studies, Vol: 10, 189-216. University Press of America.

Hughes, F.P. 2010. Children, Play and Development, Los Angeles, Sage. $4^{\text {th }}$ edition

Kress, G. 2000. Before writing: rethinking the paths to literacy. $2^{\text {nd }}$ ed. London: Routledge.

Leitch, R. 2008. Children's narratives through images. In Doing visual research with children and young people, in P. Thomson, ed. 37-58. Abingdon: Routledge.

Luquet, G.H. 1927/2001.Children's drawings ('Le Dessin Enfantin'). (A. Costall, Trans.). London: Free Association Books

MacNaughton, G. 2004. Exploring critical constructivist perspectives on learning. In Early childhood education: Society and culture, eds A. Anning, J. Cullen and M. Fleer, 4354. London: Sage.

Matthews, J. 1999. The art of childhood and adolescence: The construction of meaning. London: Falmer Press.

Moyles, J.R. 1989. Just playing? The role and status of play in early childhood education. Buckingham: Open University Press.

Pahl, K. 1999. Transformations: Meaning making in nursery education. Stoke: Trentham Books.

Pariser, D. 1995. Not under the lamppost: Piagetian and neo-Piagetian research in the arts. A review and critique. Journal of Aesthetic Education, 29(3), 93-107. 
Pariser, D. (1999) Children of Kronos: What two artists and two cultures did with their childhood art. Journal of Aesthetic Education, 33(1), 62-72.

Scott Frisch, N. 2006. Drawing in preschools: A didactic experience. The International Journal of Art \& Design Education 25, no. 1: 74-85.

Sutton-Smith, B. 1997. The Ambiguity of Play, Cambridge: Harvard University Press.

Vygotsky, L. S. 1934/1976. Play and its role in the mental development of the child. In J.S. Bruner, A. Jolly and K. Sylva, eds. 1976. Play: its role in development and evolution, 537554. Harmondsworth, Penguin.

Vygotsky, L.S. (1978) Mind in Society: The development of higher psychological processes. M. Cole, V. John-Steiner, S. Scribner and E. Souberman, eds. Cambridge MA. Harvard University Press.

Wang, H.B. 2007. Conceptions of art in Hong Kong preschool children. Australian Journal of Early Childhood 32, no. 4: 31-36.

Watts, R. 2010. Responding to children's drawings. Education 3-13 38, no. 2: 137-153.

Wood, E. 2005. Young children's voices and perspectives in research: methodological and ethical considerations. International Journal of Equity and Innovation in Early Childhood 3, no. 2: 64-76.

Wood, E. (2009) Conceptualising a pedagogy of play: international perspectives from theory, policy and practice. In D. Kuschner, ed. From children to red hatters. Play and Culture Studies, Vol 8, 166-189. Maryland: University Press of America.

Wood, E. 2010. Reconceptualising the play-pedagogy relationship: from control to complexity, in L. Brooker and S. Edwards, eds. Engaging Play, 11-24, Maidenhead, Open University Press.

Wright, S. 2007. Young children's meaning-making through drawing and "telling": Analogies to filmic textual features. Australian Journal of Early Childhood 32, no. 4, 33-48. 